УДК 1.101.1

\title{
DOI 10.18522/2227-8656.2020.5.6
}

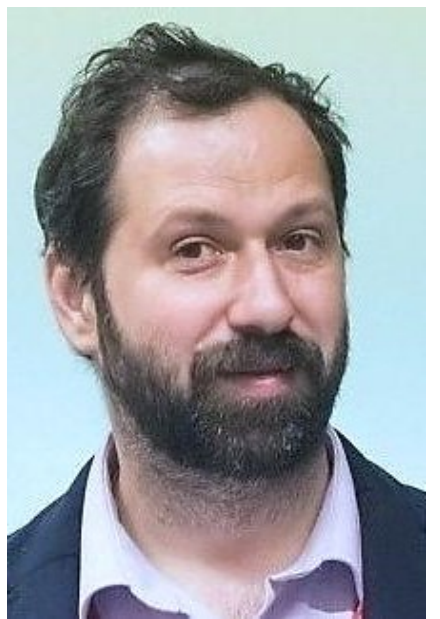

\section{ТРАНСЦЕНДЕНТНОСТЬ ИСТОРИЧЕСКОГО ОПЫТА: ОГРАНИЧЕНИЯ НАРРАТИВНОГО АНАЛИЗА И ПРОБЛЕМАТИЗАЦИЯ НОВЫХ ОНТОЛОГИЙ*}

\author{
Марков Александр Викторович \\ Доктор филологических наук, профессор, \\ кафедра кино и современного искусства, \\ Российский государственный \\ гуманитарный университет, \\ г. Москва, Россия, \\ e-mail: markovius@gmail.com
}

Нарративный подход к анализу исторического факта обычно исходит из нескольких неоговариваемых предпосылок, таких как возможность различения синтаксиса и семантической автономии, возможность коррекции описания при невозможности коррекции принятого определения, установление определенных синхронизаций процессов познания и процессов описания. Этот подход обладает целым рядом ограничений, не все из которых осознаны и осмыслены до
TRANSCENDENCE OF HISTORICAL EXPERIENCE: LIMITATIONS OF NARRATIVE ANALYSIS AND PROBLEMATIZATION OF NEW ONTOLOGIES ${ }^{\dagger}$

\author{
Alexander V. Markov \\ Doctor of Philology, Professor, \\ Department of Cinema and Contemporary Art, \\ Russian State University \\ for the Humanities, \\ Moscow, Russia, \\ e-mail: markovius@gmail.com
}

A narrative approach to the analysis of a historical fact usually proceeds from several nonstipulated prerequisites, such as the possibility of distinguishing between syntax and semantic autonomy, as the possibility of correcting a description if it is impossible to correct the accepted definition, as establishing certain synchronizations of cognition and description processes. This approach has a number of limitations, not all of which are fully understood and comprehended in modern philosophical think-

* Статья написана при поддержке Российского фонда фундаментальных исследований, проект «Трансцендентность и нарратив в становлении моделей историзма» РФФИ № 19-011-00610.

${ }^{\dagger}$ The article was written with the support of the Russian Foundation for Basic Research, Project "Transcendence and Narrative in the Formation of Models of Historicism" RFBR No. 19-011-00610. 
конца в современном философском мышлении: принципиальное разведение различных категориальных пониманий исторического времени, которые соединяются только определенными фигурами якобы критического рассуждения, линейные и прогрессивные модели даже там, где они заведомо будут работать не во всех случаях, наличие недоказуемых аксиоматических положений, взятых из гетерогенных практик (например, автономия в политическом понимании или структурность в широком экономическом понимании). Новые онтологии пытаются предвосхитить ситуацию, сразу отменяя такие ограничения, как категориальная интерпретация, инструментализующаяся как внетрансцендентная, или приписывание трансцендентных свойств тем аксиомам, которые нужно оторвать от гетерогенных практик. Но новые онтологии, претендуя на то, чтобы не сводить трансцендентность ни к фигуральному инструменту интерпретаций, ни к моменту доказательства на основе критически проверенных аксиом, не могут справиться с инерцией нарративного анализа, в результате чего, отвергая инструментализм и аксиоматизм, новые онтологии при этом удерживают фигуры «достаточности» или «недостаточности» и понимание трансцендентного как сверхинструментального, способного сгенерировать новую аксиому на основании всей суммы опыта. В статье мы показываем, как возможна та трансцендентализация исторического опыта, при которой данное удержание лишается смысла и новые онтологии сами оказываются уже вне этой нарративной инерции определенными типами доказательности, распределяющими аксиомы и теоремы как моменты, а не инструменты новой теории.

Ключевые слова: трансцендентность; историзм; исторический опыт; аксиоматика действия; инструментализация теории; онтология; философия в культуре. ing: the fundamental dilution of various categorical understandings of historical time, which are connected only by certain figures of supposedly critical reasoning, linear and progressive models even where they will obviously work not in all cases, the presence of unprovable axiomatic positions taken from heterogeneous practices (for example, autonomy in the political sense or structuralness in the broadly understood economic sense). New ontologies try to anticipate the situation by immediately eliminating restrictions such as categorical interpretation, instrumentalized as extratranscendental, or as attributing transcendental properties to those axioms that need to be torn away from heterogeneous practices. But new ontologies, pretending not to reduce transcendence either to a figurative instrument of interpretation, or to the moment of proof based on critically tested axioms, cannot cope with the inertia of narrative analysis, as a result of which, while rejecting instrumentalism and axiomism, new ontologies retain figures of "sufficiency" or "insufficiency" and the understanding of the transcendental as superinstrumental, capable of generating a new axiom based on the entire sum of experience. In the article, we show how the transcendentalization of historical experience is possible, in which a given retention loses its meaning and new ontologies themselves are already outside this narrative inertia by certain types of evidence that distribute axioms and theorems as moments, and not tools of a new theory.

Keywords: transcendence; historicism; historical experience; axiomatics of action; instrumentalization of theory; ontology; philosophy in culture. 


\section{Введение}

В основе нарративного опыта, который мы всякий раз встречаем в нашей цивилизации, стоит противопоставление греческого и римского опыта, или греческого опыта работы с неготовыми жанрами, всякий раз растворяющимися то в диалектных решениях и обычаях, то в сопровождающей их бытовой или иной речевой ситуации, и в противоположность ему, римской работы с готовыми жанрами, которые принимаются во всей своей канонической устойчивости так, что их жесткие условности просто заранее признаются утилитарно уместными, несмотря на все трудности выполнения условий. Такая ситуация, хотя и недостаточно обсуждается при решении частных философских задач, определяет те дискуссии, которые связаны со становлением новых онтологий в наши дни. Речь идет о таких авторах, как Г. Харман, Р. Брассье, Б. Латур, С. Жижек, и вообще обо всех дискуссиях, которые идут внутри уже новых медиа: по видеосвязи, в социальных сетях, в учебных и научных проектах нового типа, основанных на сетевом распределении проблем и их решений, даже если созданы на основе традиционных учреждений по передаче знания. Когда Харман говорит, что современная ось различения между философскими системами проходит не по линии идеализм/материализм или даже религия/атеизм, а по линии привилегированный/непривилегированный доступ к вещам (Харман, 2019. С. 480), то он не просто спорит с Жижеком, а показывает, что различные подходы прежде всего определяются нарративами, и тогда непривилегированный доступ можно сблизить с культурой «неготового слова» греков, тогда как привилегированный (традиционный метафизический) - с римской иерархией канонических высказываний. Разумеется, это не означает ни в коем случае никаких эстетических симпатий к «эллинизму» в противовес Риму, какие мы знаем в романтической мысли от Винкельмана до Хайдеггера, - эти симпатии принадлежат уже истории мысли, даже в случае могущественного философского проекта Хайдеггера, и не могут непосредственно определять наши оценки. Более того, когда Харман утверждал, что Латур как автор теории, «в которой мосты всегда возводятся на конкретных местах» (Харман, 2014. С. 247), он тем самым утверждал плюральность как общий принцип работы своей и Латура, но как принцип критики нарратива, установления границ каждого нарратива. Тогда благодаря совместной работе современной философии, работе этих новых онтологов и можно подняться над условными греческими и римскими предпосылками, производящими ограниченное понимание 
трансцендентного, и далее посмотреть, как возможно понимание трансцендентного с учетом уже осмысленного исторического опыта.

В данной статье мы рассматриваем то, как стал возможен нарративный подход не в качестве анализа границ структурирования знания или появления запроса на знание, что соответствовало бы общему дрейфу нарративного подхода в кибернетическую сторону, но как он стал частью дискуссий условно греческих и римских в эпоху научной революции и ее рецепции в Просвещении конца XVIII в. И Харман, и Латур, и Мейясу ориентируются на научную революцию (в понимании, обоснованном в свое время А. Койре) как на тот момент, когда и появились объективные ограничения на занятия философа всеми науками, задолго до того, как философы задним числом стали эту невозможность обосновывать. Шутка Хармана о невозможности для Жижека стать химиком (Харман, 2014. С. 231) говорит именно об этом и, по сути, о границах нарративного подхода: мы думаем, что наш нарратив может иметь дело с химическими формулами, раз он уже имел дело с математическими формулами, но на самом деле этого не получается, потому что и историческая, в том числе институциональная, автономия химии иная, чем у математики, и само производство прогресса там другое. Дело не в том, что химики не посвятят Жижека в свои тайны, а в том, что химия окажется заведомо дальше, чем философ, который будет занят трансцендентным обоснованием химии, а не справившись с этим, просто объявит себя очередным «новым материалистом».

\section{Отношение методической позиции и проблематизации}

При этом если невозможность дедукции некоторой методической позиции в отношении к трансцендентному обоснованию природы как таковой, независимо от того, насколько качественные нарративы о природе оказались в нашем распоряжении, вполне доказана Бибихиным (Бибихин, 2011. С. 50-56), то более сложный вопрос, как именно становится возможна аксиоматика, без которой нельзя говорить о трансцендентном вообще, в ситуации плюральности нарративов, еще не рассмотрен в мировой науке. Читая Хармана, Латура и Мейясу, мы постоянно сталкиваемся с обоснованием этой аксиоматики из довольно простых оппозиций, таких как оппозиция достаточности или недостаточности, которая просто пересекает области речи и мышления, так что можно успешно говорить о достаточном взгляде на какую-то вещь или достаточном высказывании о ней. Но именно здесь мы, вроде бы преодолев трудности обоснования аксиоматики, приняв за аксиому, что вообще достаточное отношение к вещам возможно, сталкиваемся с новой трудно- 
стью, что мы вводим трансцендентальное как ситуативное, которое всякий раз и обосновывает, что раз мы смогли разглядеть какое-то явление, то мы можем о нем и сказать. Конечно, представители новых онтологий могут ссылаться и на Гуссерля, и на философию языка, показывая, что мы как бы можем вынести за скобки эту ситуативность, обойтись без нее в новом обосновании границ опыта. Но в нашей действительной философской работе это вынесение за скобки окажется вовсе не той операцией, о которой говорил Гуссерль, а просто одним из нарративов, например нарратив отрешенности.

Поэтому, обосновывая далее возможность речи, различающей трансцендентное и трансцендентальное не в соответствии с выводами из тех или иных строгих нарративов, даже кантовского, а из критики нарративов, мы обращаемся к тому, как условные греческий и римский способы организации нарративов времен научной революции сами находят свои границы и как это нахождение разыгрывает современные споры в новой онтологии. Тем самым мы сможем установить, как возможна критика нарратива, исходящая не из частных или ограниченных способов обоснования аксиоматики, но как может быть с учетом исторических данных быть обоснована аксиоматика, которая различает трансцендентное и трансцендентальное и возвращает достоинство трансцендентальной философии в современный мир.

В эпоху научной революции, с одной стороны, оказалось, что движение от предпосылок к выводу гораздо сложнее, чем просто реализация следствий аксиоматики с помощью всех имеющихся ресурсов языка, как было в античной философии или схоластике. Появился более сложный путь, основанный на недоверии языку, точнее, на превращении его в трансцендентальный феномен, в то, что мы необходимо созерцаем для того, чтобы наше научное созерцание было одновременно научным действием. Но если в условно римской традиции было нетрудно обосновать каноничность такого недоверия, исходя просто из устаревания схоластики как «жанра» и возможности устроить новые науки в новых институциональных рамках действия, то в условно греческой традиции, в которой науки - это были прежде всего «диалекты», некоторые способы рассуждения о вещах со своей даже бытовой и стилистической окраской, ситуация оказалась сложнее. Конечно, можно говорить о консерватизме или маргинальности данной традиции, но на самом деле перед нами не меньшая проблематизация привычных эффектов нарративов, чем в западной традиции, и поэтому смысл споров в современных новых онтологиях мы видим, только обратившись к этой традиции, а не только к Паскалю и Ньютону. 


\section{Научная революция как парадигма философской революции в ситуации диалектов}

Греческий поклонник Ньютона А. Псалидас больше чем за два века до Хармана произвел его опыт критики корреляции, но не на основании недостаточности академической науки, а исходя из просто изменения исторической эпохи: Аристотель уже не может быть признан метафизиком, если метафизиком оказался Ньютон, должен быть лишен этого звания, и метафизика понималась Псалидасом вполне в стиле хармановского корреляционизма: чтобы не познавать бесконечное бесконечным количество времени, к чему поневоле подталкивал Аристотель с его инерцией идеализма, лучше познавать конечное конечным количество времени и с помощью конечного числа слов или формул. И как Харману для его исследований понадобился Лавкрафт как писатель, «странности» которого проявляются не столько в сюжете, но и в том, что и ключевые образы, и отдельные фразы вдруг раскрываются неожиданной стороной, как трансцендентальная самодостаточность опыта, свидетельствующая о трансцендентном обосновании философской аксиоматики (Харман, 2020. С. 67-70), так и Псалидасу понадобился Декарт, которого он толкует почти как Гуссерль - как методолога частных наук - от метеорологии до разделов медицины, которые оказываются странными, распоряжающимися метафорами, такими как «вихрь» или «поток», так что философская аксиома не может быть обоснована исходя из Декарта, который только толкует готовые аксиомы. Она требует именно перечитывания Декарта, только не на основе установления структур самого философского внимания, как это делал Гуссерль, а на основе различения между физикой и физиологией, которое соответствует паламитскому различению между сущностью и энергией.

Хотя Псалидас никак не ссылался на учение Г. Паламы, следствия этого различения сущности и энергии и составляют единственную основательную аксиоматику во всех его построениях, о чём бы он ни писал. В своем труде «Истинное счастье» (1791) Псалидас так и говорит (Petsios, 1997. Р. 166), что душой и телом занимаются разные науки. Значит, связь между душой и телом может осуществляться не непосредственно, а с помощью отдельных «даров», что очень напоминает современный проект Мейясу философии «после конечности» (Мейясу, 2015), исключающей прежние представления о непосредственности цепочек познания и опыта, раз каждое звено может упереться раньше в конечность, чем дать нам трансцендентальные выводы. Склонность к детализации, вполне в духе нашего современного системного анализа Латура, потребовала от Псалидаса не просто вычленить дары, не принадлежащие порядку природы, как отдельные причины 
гражданского согласия, но увидеть жесткую до аскетизма систему: очищающийся ум по воле творит свободу. В случае Псалидаса гражданский идеал полностью совпал с очищением ума, понятым как единственный способ отнестись к трансцендентному обоснованию этики, так что трансцендентальное мышление тогда понимает структуру отдельных понятий как структуру порядков соотношений внутри системы, продолжающейся энергии, тогда как сущность непостижима, и «полезность» ума в той мере полезна, в какой аскетична, и следовательно, ум может истолковать любой поступок, хорош он или плох, не обращаясь к обстоятельствам явлений (Petsios, 1996. Р. 132), т. е., по Харману, не упрощая «запутанное» и не требуя корреляции обстоятельств появления мысли и обстоятельств явления, которые и мыслятся как основания для его оценки. Псалидас, в конце концов, заклеймил детерминистов как не умеющих различать сущность и энергию, а полностью доверяющих энергийному (и мы бы сказали, энергичному) воздействию на них как чему-то существенному, что полностью совпадает с критикой корреляционизма как приписывания существенному какой-то меры воздействия на физические состояния или дальнейшие интеллектуальные выводы в цепочке дальнейших рассуждений.

\section{От критики языка к критике влияний}

Исихастское богословие влияло на греков подспудно, никак не сказываясь на проблематизации отвлеченных тезисов, но на понимании события. Если божественный свет - не условный знак, но исключительная данность, то тогда есть наука, имеющая дело с этим исключительным событием, а значит, есть и другие науки, тоже имеющие дело с исключительными событиями. Здесь греческие интеллектуалы двухвековой, такие как Вулгарис, Макреос, Катарцис, совершали тот ход, который мы знаем по «Имматериализму» Г. Хармана, для которого материализм неправ тем, что выводит ключевые моменты человеческой жизни из созерцания, которое неизбежно принимает интроспективный оборот, как только очередной господствующий нарратив заставляет нас говорить о себе (Харман, 2018. С. 60). Тогда как на самом деле, считал Харман, ключевые события в мире и человеческой жизни обязаны симбиозам, но симбиоз нельзя изучить, просто объединив два порядка знаний, а только показав, как исключительность науки, ведающей этим симбиозом, подразумевает исключительность и соседних наук. Греческие интеллектуалы отвергали аристотелизм как учение о материи, а платонизм как учение о событии, считая, что если Платон рассматривает явления внутри по крайней мере двух порядков, идеи и опыта, то это может привести к разнузданности страстей (Kondylis, 1988. Р. 70), потому что 
наше чувство следует всегда только какому-то одному порядку принятия причин и следствий и лишается поэтому контроля со стороны другого, который и следовало бы объявить нормативным: такую разнузданность, а не воинский аскетизм Вулгарис видел в общности жен и детей в «Государстве» Платона.

При этом в остальном Вулгарис одобрял Платона (Kondylis, 1988. Р. 236), но совершенно так, как Харман или Мейясу одобряют Шеллинга и наследие идеализма, для того, чтобы найти в философии XX в. те основания суждения о трансцендентном, которые не связаны с дисциплинарными разделениями и признанием за тем или иным знанием (научным или экзистенциальным) мощи привилегированного суждения или хотя бы мощи такого суждения, которое вносит порядок в уже признанные привилегии доступа к вещам и к опыту. Борьба с корреляционизмом требует преодоления такой инерции суждения, которая вдруг незаметно превращает уже приобретенные привилегии познания в основание пусть сколь угодно критической оценки происходящего, но превращающей это происходящее в предмет некоторой специальной науки. Но то же, что делают сейчас Харман и Мейясу, делал Вулгарис, предпочитавший материализму Кондильяка сенсуализм Локка, потому что Кондильяк признает только науки и книги как источник знания, а Локк - саму душу (ум) как источник и поддержание наук и знаний. В таком случае «имматериальное» Хармана соответствует «душе» Локка в такой интерпретации: оно обеспечивает доступ вещей к нашей системе выводов о причинах и следствиях и тем самым не позволяет принять инерцию частного знания за состоявшееся познание природы вещей. Поневоле ученики Вулгариса, например, С. Макреос (Kondylis, 1988. Р. 238), далее выводили специфику познания из паламитского различения сущности и энергии: например, энергия чувств имеет предел действия, и потому не может познать даже всю материю, поэтому Платон и Аристотель не были правы, утверждая бессмертие материи, ведь оно не может быть доступно энергии нашего познания. Тогда как энергия нашего ума, наоборот, порождает любое познание, и мы не можем доказать, что она когда-либо перестанет это порождать, это будет изменой природе ума, а значит, рано или поздно породит и правильную науку о трансцендентном. Таким образом, Макреос исповедовал антикорреляционизм, основанный на том, что трансцендентное определяет способ бытия и материи, и познания, и первое бытие обосновывает себя как непосредственность вещи, а второе - как непосредственность трансцендентального.

При этом споры между греческими интеллектуалами очень интересно предвосхитили споры между сторонниками и современниками новых онто- 
логий. Так, В. Лесбосский объявлял античные учения о бессмертии материи результатом впечатлительности, увлекшей за собой нарратив, и в этом смысле вполне действовал в духе критики корреляционизма Харманом, тогда как И. Мисиодак считал, что материализм просто объединяет философов в некоторую невидимую партию, где Аристотель оказывается заодно с Вольтером, и в таком случае политическая философия, в лице Платона, радикализуется невольно настолько, что перестает быть материалистической, а раскрывает строение идеального как нормы такой радикализации, что напоминает Жижека. В этом смысле еще больше предтечей Жижека был болгарский наследник этой традиции П. Берон, обвинивший старую логику в индивидуализме, который не может принять ни одного научного открытия как слишком радикального по сравнению с привычным индивидуальным суждением (Бычваров, 1981. С. 69), и хотя эта критика логики не была оригинальна (на Западе логику за слишком индивидуальную гипотетичность бранил еще П. де ля Раме), она замечательна тем, что в духе Жижека и словенской школы психоанализа объявляет привычные суждения нарциссическими, как не обязанные трансцендирующей рефлексии (Жижек, 2008. C. 28-30). И как и в случае Жижека, отказ от энергийного обоснования трансцендентального опыта, сведение его исключительно к парадоксу рефлективной позиции, разрушал учение о трансцендентном обосновании возникновения наук: так, в Греции XIX в. богослов А. Макракис учил о том, что Христос берег свое индивидуальное я и только поэтому отвергал дьявольское искушение, что, конечно, было воспринято тогда как еретическое богословие. Поэтому греческому богословию XX в. пришлось восстанавливать трансцендентное обоснование реалистического видения, примерно как Латуру пришлось на основании кибернетики создавать трансцендентное обоснование самого пользования словами и знаками.

В книге «Рекомое и нерекомое: языковые пределы реализма метафизики», копирующей строение «Логико-философского трактата» Витгенштейна, Яннарас пытался объяснить, как границы языкового высказывания примиряют эволюционный закон природы с несомненной трансцендентностью творящего начала. Яннарас исходит из того, что эволюция, в конце концов, имеет развязку в виде каждого нового организма, которая и позволяет природе примириться с принципиальной смертностью любых организмов. Такая процедура развязки оказывается границей и отношения природы с собой, и высказывания о природе, тогда как границы человеческого отношения к природе определяются тем, что непосредственное отношение к природе, например, восторг перед ней или участие в дальнейшем ее производстве, включает в себя и опыт тоже (Giannaras, 1999. Р. 287), иначе го- 
воря, выстраивание наших впечатлений как определенным способом целесообразных.

Согласно Яннарасу, единственное, что мешает нам так понимать эволюционные процессы, - метафора «ступеней развития» (Giannaras, 1999. P. 291), превращающая способ целесообразности исключительно в основание для некоторых речевых высказываний и тем самым оставляющая их в прошлом, беллетризирующая эволюцию, превращающая ее из экзистенциального действия в литературу. Тогда как для Яннараса как раз целесообразность в интеллектуальном мире, которая позволяет ипостасному человеку доверять природе Божией, тем самым и потом, входя в ипостась Христову, обоживаясь через всё большее соотнесение с природой Божией, позволяет человеку выдержать Страшный суд именно как такую же развязку в интеллектуальном мире. Паламитский догмат здесь выступает как новая телеология, общая для природного и интеллектуального, что само существование энергий, но не сводимость отношения к энергиям, подтверждает их реальность и позволяет непосредственно быть им причастным. Заметим, что если бы русские имяславцы приняли бы вместо понятия «имя» понятие «доверие», их бы система, вероятно, не вызвала никаких богословских вопросов. Тогда как Яннарас привел в качестве примера картину Кандинского: «Мы можем предположить эволюционные стадии в отношении людей к беспредметной живописи. Люди, у которых не развита способность референции, воспринимают эту картину как нейтральный предмет, деревянную рамку, в которой есть холст с красками. На следующей стадии они различают на раскрашенном холсте отображение чувств или символических значений. И на особой стадии они опознают на картине творческий смысл личной другости конкретного живописца. То есть: эта картина - Кандинский» (Giannaras, 1999. P. 295).

\section{Заключение}

Такая стадиальность оказывается не просто выработкой органических или интеллектуальных способностей, но способностью наиболее доверчиво отнестись к тому предмету, который раньше не заслуживал такого отношения, потому что доверчивее всего относились к чему-то другому. Таким образом, можно говорить, что трансцендентное обоснование наук теперь преодолевает и материалистическое, и эстетическое обоснование цепочек причинности, позволяя наукам непосредственно выходить к предмету помимо корреляционизма: только у Латура это возможно благодаря кибернетической архитектуре мира, а у Яннараса - благодаря некоторому изначальному благородству доверия. В обоих случаях распределение аксиом и теорем никак не зависит от натуралистических или каких-либо еще цепочек порожде- 
ния бытия или знания. Диалога между Латуром и Яннарасом пока нет и вряд ли будет, но зато мы можем сказать, как именно состоялось трансцендентное обоснование знания, в котором трансцендентальным окажется любой нарратив, не утверждающий норму привилегированного доступа.

\section{Литература}

Бибихин В.В. Лес. СПб.: Наука, 2011. $425 \mathrm{c}$.

Бычваров М., Бычварова Н. Петер Берон. М.: Мысль, 1981. 232 с.

Жижек C. Устройство разрыва: параллаксное видение. М.: Европа, 2008. 516 с.

Мейясу $K$. После конечности: эссе о необходимости контингентности. Екатеринбург, Москва: Кабинетный ученый, 2015.

Харман Г. Государь сетей: Бруно Латур и метафизика // Логос. 2014. № 4. С. 229-248.

Харман Г. Имматериализм: объекты и социальная теория. М.: Изд-во Ин-та Гайдара, 2018. $150 \mathrm{c}$.

Харман Г. Спекулятивный реализм: введение. М.: Рипол, 2019. 496 с.

Харман Г. Weird-реализм: Лавкрафт и философия. Пермь: Hyle Press, 2020.

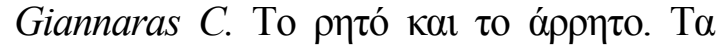

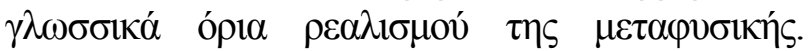
Athens: Ikaros Books, 1999. 328 p.

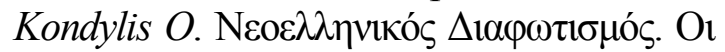

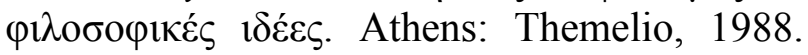
$232 \mathrm{p}$.

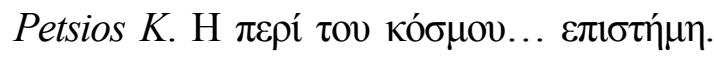

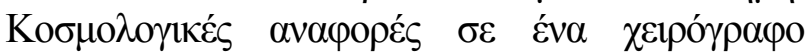

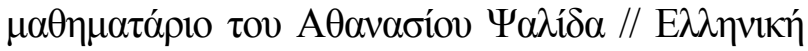

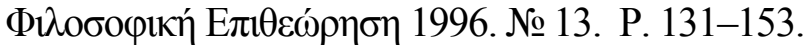

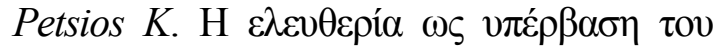

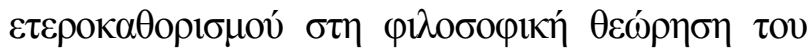

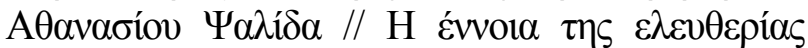

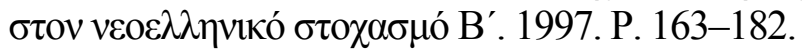

\section{References}

Bibikhin, V.V. (2011). The Woods. St. Petersburg: Nauka Publ. (in Russian).

Bychvarov, M., Bychvarova, N. (2011). Peter

Beron. Moscow: Mysl' Publ. (in Russian).

Žižek, S. (2008). Gap device: Parallax vision. Moscow: Evropa Publ. (in Russian).

Meillassoux, Q. (2015). After the final: an essay on the need for contingent. Yekaterinburg, Moscow: Kabinetnyy uchenyy Publ. (in Russian).

Harman, G. (2014). Sovereign of networks: Bruno Latour and metaphysics. Logos, 4, 229-248 (in Russian).

Harman, G. (2018). Immaterialism: Objects and Social Theory. Moscow: Gaidar Institute Publishing House. (in Russian).

Harman, G. (2019). Speculative Realism: An Introduction. Moscow: Ripol Publ. (in Russian).

Harman, G. (2020). Weird-Realism: Lovecraft and Philosophy. Perm: Hyle Press. (in Russian).

Giannaras, C. (1999). The saying and the unspoken. The linguistic limits of metaphysical realism. Athens: Ikaros Books. (in Greek).

Kondylis, O. (1988). New Greek Enlightenment. The philosophical ideas. Athens: Themelio. (in Greek).

Petsios, $K$. (1996). The science of the world. Cosmological references in a handwritten textbook by Athanasios Psalidas. Hellenic Philosophical Review, 13, 131-153. (in Greek).

Petsios, K. (1997). Freedom as a transcendence of heterodetermination in the philosophical view of Athanasios Psalidas. The concept of freedom in modern Greek thought, 2, 163-182. (in Greek). 